\title{
Functional Characterization of 1.1B4 - Novel Human Insulin Releasing Cell Line and Effect of High Density Green Photons Irradiation on Beta Pancreatic Cells and Human Pancreatic Islets
}

\author{
Petruta Alexandru ${ }^{1}$, Liliana Paslaru², Simona Dima², Anca Nastase ${ }^{2}$, Laura Stoichita², \\ Sorin Comorosan ${ }^{2,3}$ and Irinel Popescu $\mathrm{u}^{2,3}$
}

Institute of Biochemistry of the Romanian Academy, Bucharest, Romania

${ }^{2}$ Center of Digestive Diseases and Liver Transplantation, Fundeni Clinical Institute,

Bucharest, Romania

${ }^{3}$ Romanian Academy

\author{
Corresponding author: \\ Professor Liliana Paslaru \\ Fundeni Clinical Institute \\ 022328, Bucharest, Romania \\ E-mail: lilianaliviapaslaru@yahoo.fr
}

\section{ABSTRACT}

The 1.1B4 cell line is a novel human hybrid formed by electrofusion of primary culture of human pancreatic islets with PANC-1. Our analysis of functional parameters of this cell line (insulin expression and secretion, glucose responsiveness, staining with human specific antibodies) confirmed the human identity and the inherited properties of functional beta cells. Irradiation with HDGP (High Density Green Photons) of two beta pancreatic cells lines (1.1B4 and INS-1E) and of human pancreatic islets induced modifications in insulin, pro-insulin and glucagon expression and secretion.

Key words: human pancreatic beta cells 1.1B4, human pancreatic islets, HDGP, insulin

\section{INTRODUCTION}

In mammalian organisms, the only hypoglycemic hormone is insulin, produced in Beta cells of pancreatic Langerhans islets. The most part of islets are Beta cells (65-90\%, forming the core of the islet) (1).

Diabetes is characterized by a masive decrease of beta cells number correlated with functional impairement. To cure diabetes, at present, the best therapeutic possibility is pancreatic islets transplantation. They are purchased from dead donors. After isolation, islets are difficult to maintain in culture for long time and their in vitro proliferation rate is very low (2).

The Beta cells are rather delicate and susceptible to functional deficits or to stressful actions as isolation and trasplantation. The maintenance of beta cells viability and function is critically important.

The aim of this study was to find if the HDGP irradiation might induce, in
Received: 20.06.2016 Accepted: 30.08 .2016

Copyright (c) Celsius Publishing House 
normal culture conditions, functional modifications in pancreatic beta cells and in pancreatic islets.

Recent studies revealed that light may be used for modulation and control of biological function, in the production of biopharmaceuticals and in biomedicine (3).

Our previous studies demonstrated that irradiation with High Density Green Photons (HDGP) have complex pleiotropic effects on matter: generation of a new local macromolecular architecture with a protective role toward subsequent aggressions, modification of transmembranar transport, etc (4-8).

Stimulation of cell proliferation under green light LED irradiation and various effects of green light laser irradiation on different substrates were also described (9-13).

\section{MATERIALS AND METHODS}

\section{Cell cultures}

A human pancreatic 1.1B4 hybrid cell line, a rat insulinoma cell line INS-1E and human pancreatic islets were used in our study for characterization and comparison respectively and for HDGP irradiation effects. INS-1E cells were a kind gift of Peter van der Sluijs (Department of Cell Biology, University Medical Center, Utrecht, Netherlands) while 1.1B4 cells were obtained from ECACC (European Collection of Cell Cultures).

The 1.1B4 is a novel human hybrid cell line formed by electrofusion of primary culture of human pancreatic islets with PANC-1. It is an insulin secreting cell line, developed by Mc Cluskey et al (14) with application in the study of pancreatic cell biology (15). Both cell lines were maintained in RPMI-1640 medium (Sigma) containing $11,1 \mathrm{mM}$ glucose supplemented with $10 \%$ FBS (Gibco) and 1\% v/v penicillin streptomycin solution (Sigma).

Human primary pancreatic islets were obtained from Prodo Laboratories Inc USA. PIM (S), PIM (ABS), PIM (G) culture media and experimental protocols were also purchased by Prodo Laboratories.

The islets were cultured on inserts (Millipore) in 24 well plates (Corning) or in suspension (Ultra low attachement 24 well plates or flasks (Corning) in different type of media: PIM (Prodo Laboratories), CMRL 1066 Supplemented (Corning) and irradiated with HDGP.

\section{Immunostaining}

1.1B4 and INS1E cell lines and the pancreatic islets were plated on $3.5 \mathrm{~mm}$ poly-L-lysine - coated cover slips in RPMI-1640 or in CMRL medium. After 48h, the cells were either starved in media without glucose for 2 hours and then stimulated with $2.8 \mathrm{mM}$ and $28 \mathrm{M}$ glucose or cultured in media with $11.1 \mathrm{mM}$ glucose. During insulin secretion the cells and islets were irradiated with HDGP for different periods of time (minutes). Cells and islets were fixed with $4 \%$ paraformaldehyde and permeabilized with Triton-X 100 treatment. The primary antibodies were: anti-insulin (Santa Cruz, C-12), anti-insulin (Santa Cruz, H86, Cell Signaling L6B10 and AbCam 181547), anti-peptid C (AbCam 8297) anti-calnexin (Santa Cruz), anti-syntaxin 4 (Santa Cruz, C16) anti-GLUT2 (Santa Cruz, C19) and GRP94 (Santa Cruz sc 32249) Nuclei were stained with DAPI. The secondary antibodies were conjugated with AlexaFluor 488 or AlexaFluor 594 (Invitrogen). The cells were analyzed by ApoTome (Zeiss) microscope.

\section{ELISA}

For the analysis of insulin, pro-insulin and glucagon level, 1.1B4, INS-1E cells and pancreatic islets were cultured in 6 - or 24 well plates, starved for $2 \mathrm{~h}$ and than stimulated with $14 \mathrm{mM}$, and $28 \mathrm{mM}$ glucose for $24 \mathrm{~h}$. The culture medium and the cells were harvested for ELISA test (MERCODIA ELISA kit for human insulin, pro-insulin, glucagon and mouse/rat insulin and proinsulin).

\section{Western blot}

For western blotting the cells (stimulated with glucose and irradiated or not with HDGP) were lysed and the same protein quantity was loaded on polyacrylamide gels. The proteins were transferred on a nitrocellulose membrane and immunoblotted with anti-insulin antibodies ( $\mathrm{H}-86$, insulin B, Santa $\mathrm{Cruz}$, and L6B10) and C-peptid C, (Cell Signalling).

\section{High density green photon source and irradiation}

Cells under different culture conditions and the pancreatic islets were irradiated with a source of HDGP. As a source of HDGP, a pure monochromatic light emitting diodes (LED) was used (16V, 20W, 1000 lumens, Everredtronics, E 20 WG 120 C). Diodes were mounted on ventilated copper radiators. A monochromatic green light with absorption peak centered at $\lambda-520 \mathrm{~nm}$ was obtained, with intensities up to $140 \mathrm{~mW} / \mathrm{cm}^{2}$, spectral 
width $10 \mathrm{~nm}$. Time of cells irradiation varied between 1-60 min, at different intervals of time (e.g 5 minutes, 10 min, $2 \times 10$ minutes $/ 24$ hrs of incubation).

\section{RESULTS}

\section{Characterization of $1.1 B 4$ cell line}

1. Cell cultures analysis demonstrated that 1.1B4 cells grew as monolayers, maintained a stable growth rate and the phenotype during passages as previously described (14).

2. Immunofluorescence experiments demonstrated that 1.1B4 cells exhibit cytoplasmic positive staining for human insulin (using different human anti-insulin antibodies), C-peptide, calnexin, syntaxin 4, GLUT2 and GRP94 (fig. $1 a, b, c$, fig. 4).

3. For comparation, a rat insulinoma beta cells line INS-1E4 stained for insulin, calnexin, syntaxin is presented (fig. 2, a,b).

4. The insulin secretory response to different concentrations of glucose demonstrated the functional integrity of 1.1B4 cells. Comparative experiments revealed that for the same glucose concentration, the insulin secretion of 1.1B4 is much lower than in INS-1E (fig. 3a). Stimulation of 1.1B4 cell lines with increasing glucose concentrations, 2.8, 14 and $28 \mathrm{mM}$ showed an increasing level of insulin, when measured at $24 \mathrm{~h}$ (fig. 3b).

5. In our study we observed an interesting behavior of 1.1B4 cells: in certain culture conditions appears a selective enhancement of insulin expression. This observation was demonstrated by staining the cells with 3 different anti-insulin antibodies (fig. $4 a, b, c$ ).

Additionaly, to demonstrate this peculiar aspect of insulin expression in 1.1B4 cultures we present the results of experiments showing that calnexin expression is almost identical but insulin expression is variable. (fig. $5 a, b, c)$.

\section{The effect of HDGP irradiation on 1.1B4 and INS-1E beta cells}

In our experimental conditions, after HDGP irradiation a modification of intracellular and extracellular
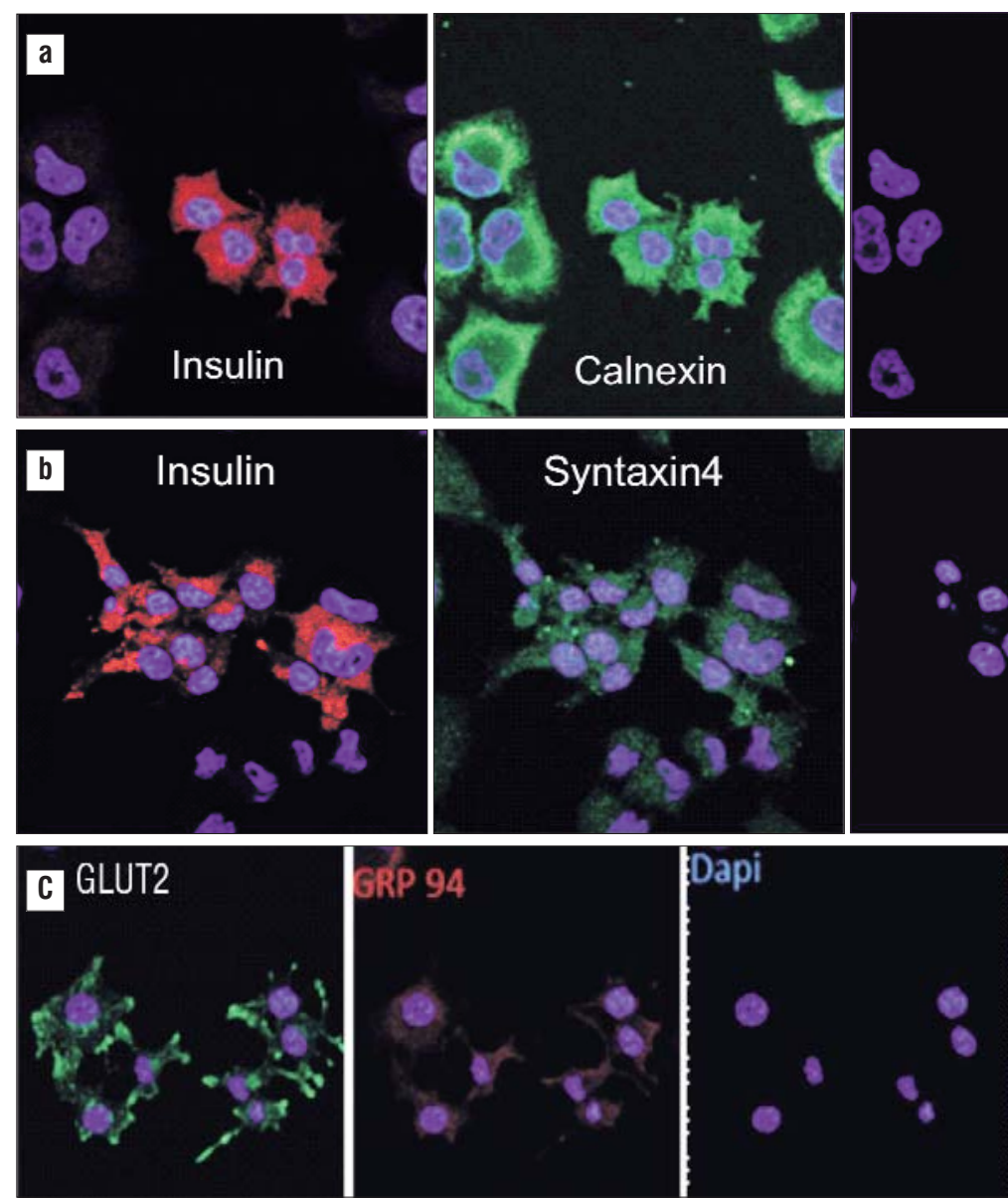

Figure 1 - Insulin, calnexin (a), insulin, syntaxin (b), GLUT2 and GRP 94 (c) expression in 1.1B4 cells
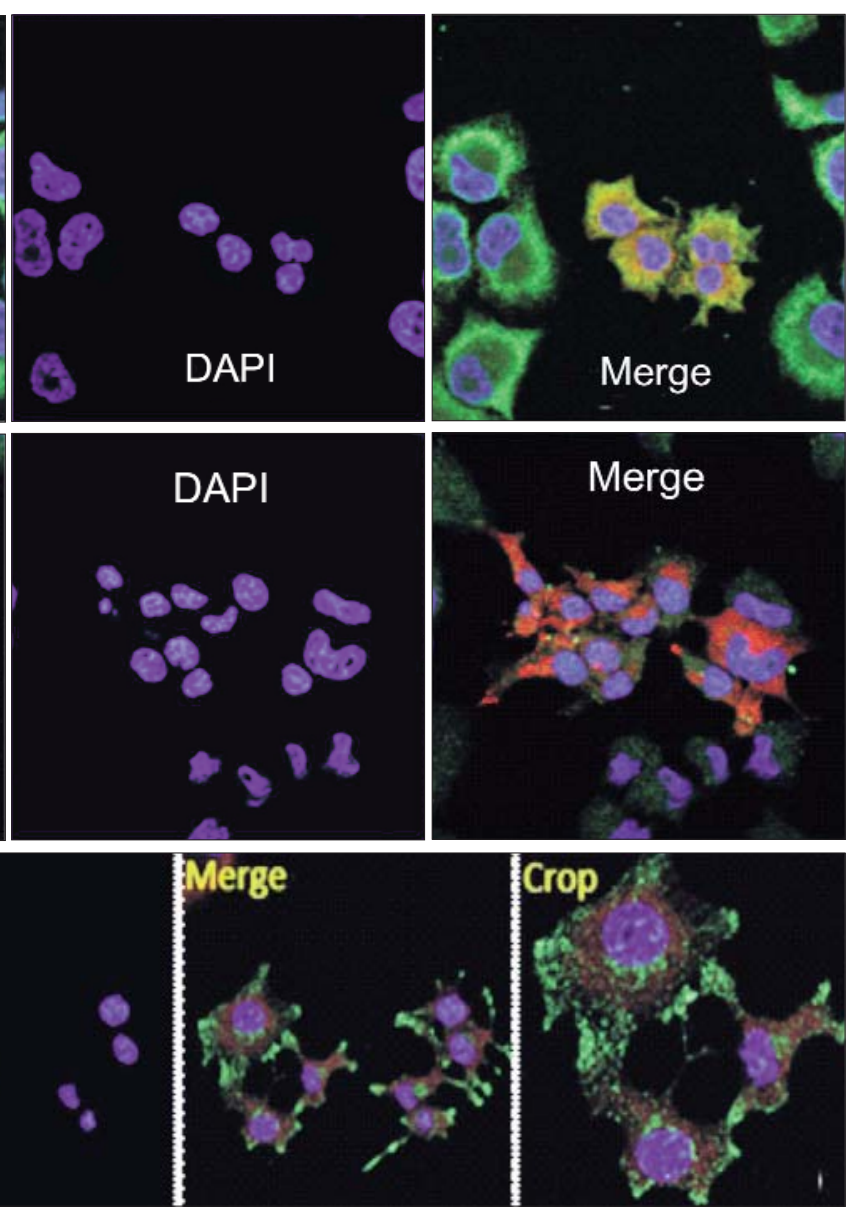

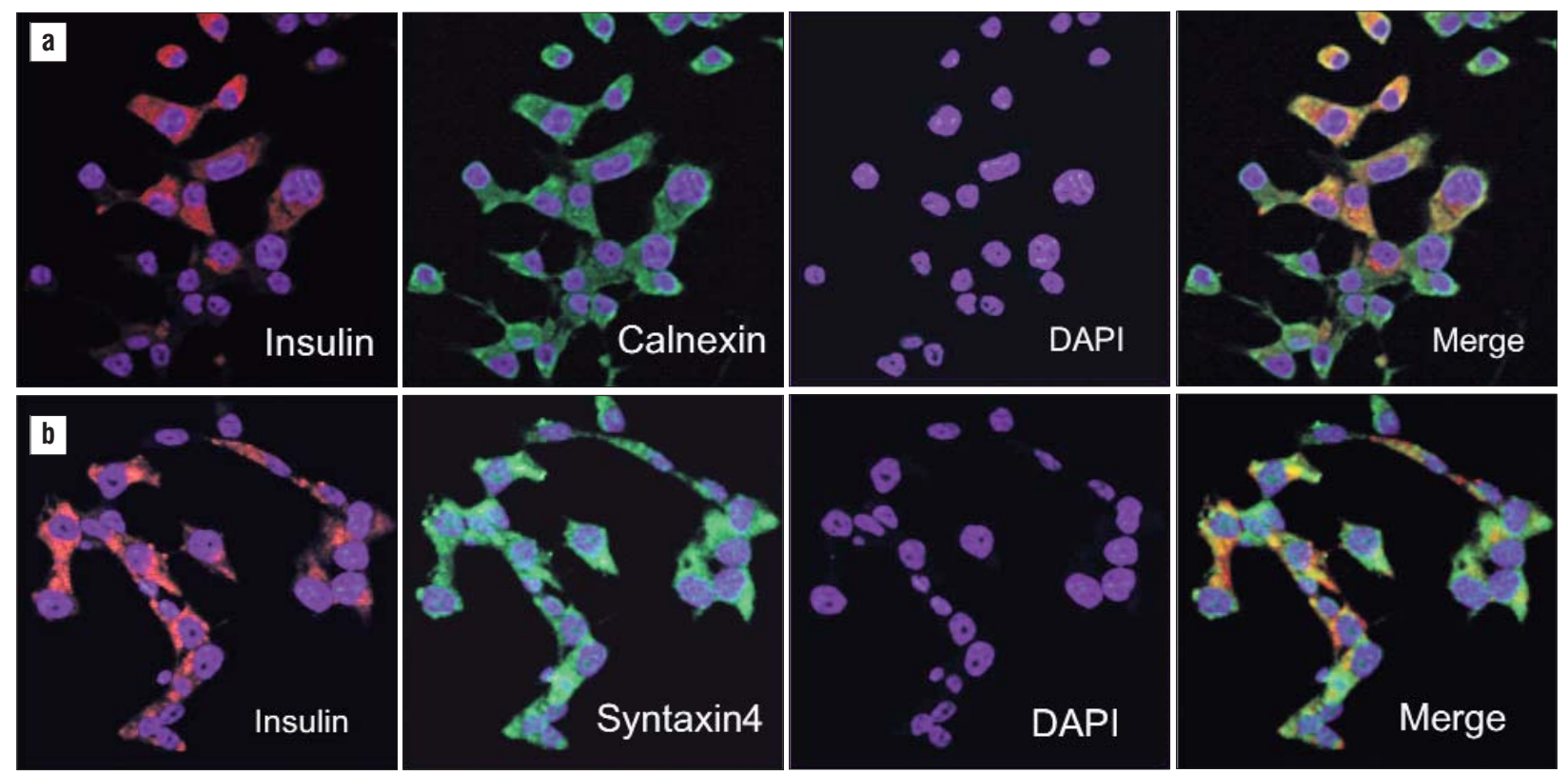

Figure 2 - Insulin, calnexin (a) and insulin syntaxin exression in INS-1E rat insulinoma cells
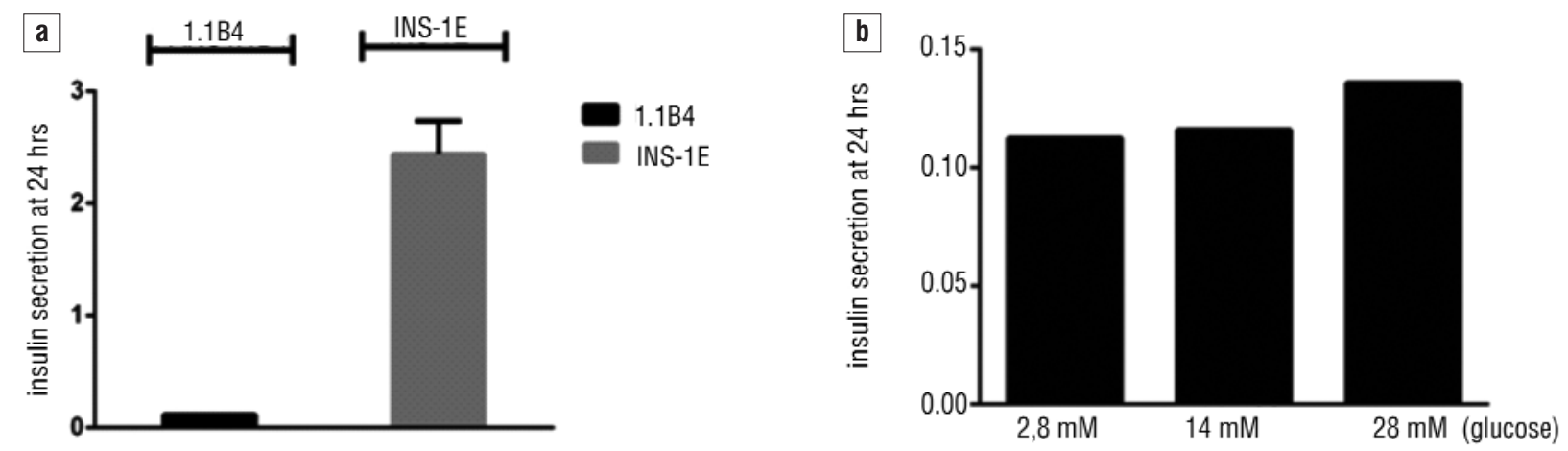

Figure 3 - (a) Comparative ELISA analysis of insulin secretion in 1.1B4 and INS-1E cell lines. (b) Determination by ELISA of insulin secretion of $1.1 \mathrm{~B} 4$ cells at 24 hrs after stimulation with $2.8,14$ and $28 \mathrm{mM}$ glucose (the second phase of secretion)

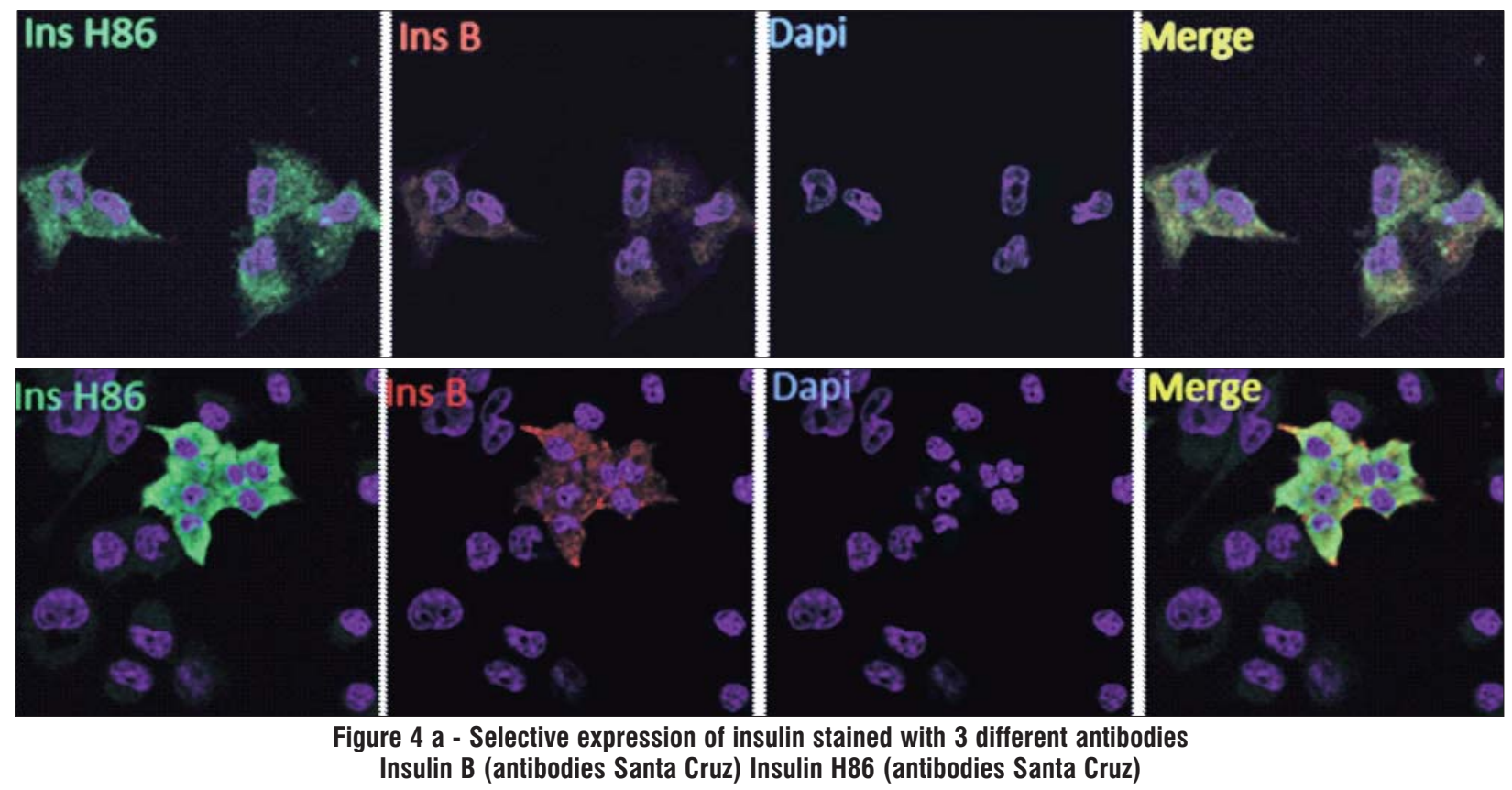



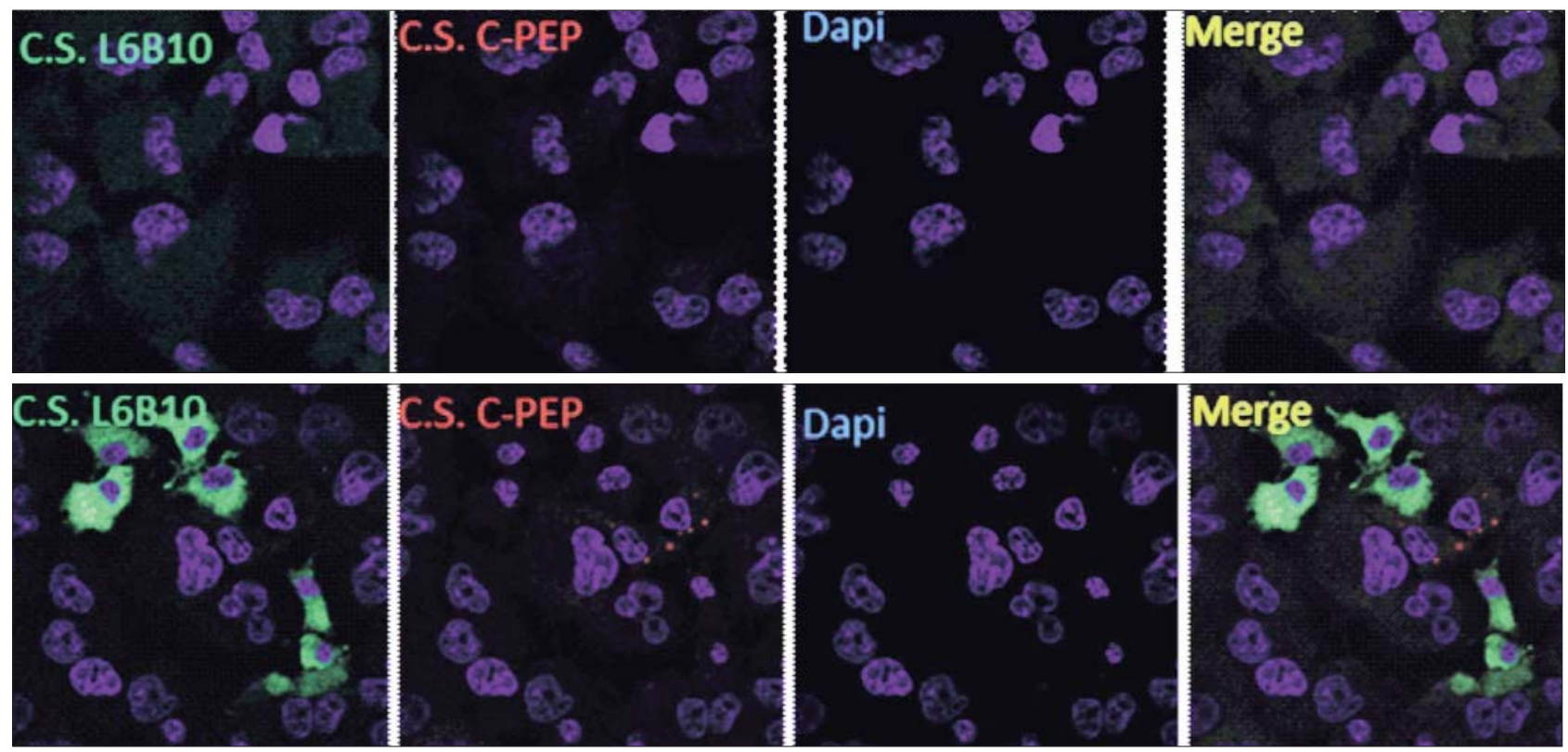

Figure $4 \mathrm{~b}$ - Selective expression of insulin stained with 3 different antibodies Insulin (Cell Signalling antibodies L6B10), C-peptid (Cell Signalling antibodies)
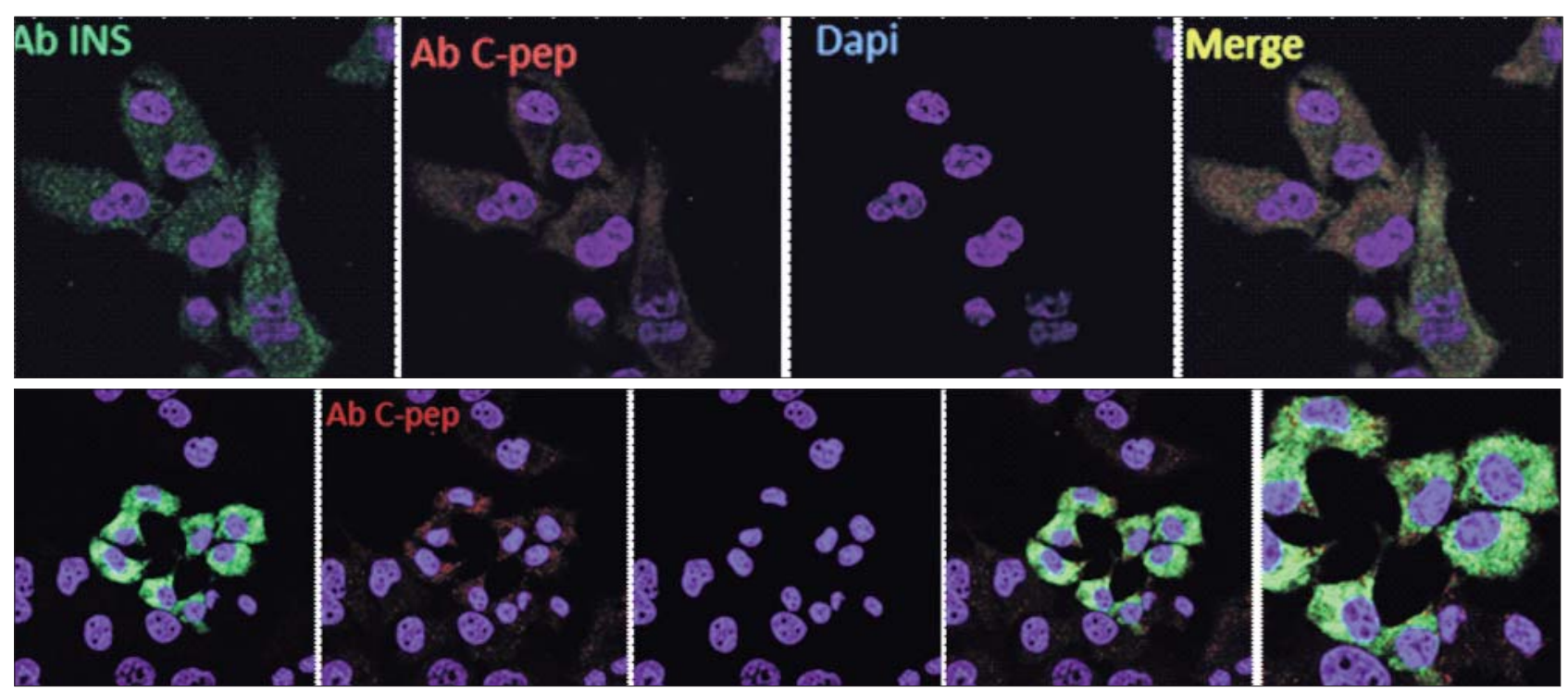

Figure $4 \mathrm{c}$ - Selective expression of insulin stained with 3 different antibodies

(c) Insulin (Abcam antibodies 18154), C-peptid (Abcam antibodies 8297)

insulin level was observed in 1.1B4 and INS-1 cells.

Augmentation of insulin was detected by immunofluorescence (fig. $6 a, b$ ) and Western Blotting (fig. 7 $a, b, c)$.

\section{The effect of HDGP irradiation on human primary pancreatic islets}

Microscopy analysis and dithizone staining demonstrated the integrity of pancreatic islet (fig. 8).

Double immunofluorescence staining of whole islets for insulin/glucagon demostrated the functionality of islets (fig. 9).

Irradiation of pancreatic islets with HDGP induced augmentation of intracellular and extracellular insulin and pro-insulin (fig. $10 a, b$ ).

Augmentation under $28 \mathrm{mM}$ glucose suggests a correct processing of pro-insulin to insulin and C-peptid and a possible protective effect of green light in chronic hyperglycemia.

The ELISA analysis of the same samples demonstrates also modifications of glucagon level (fig. $11 a, b$ ). 


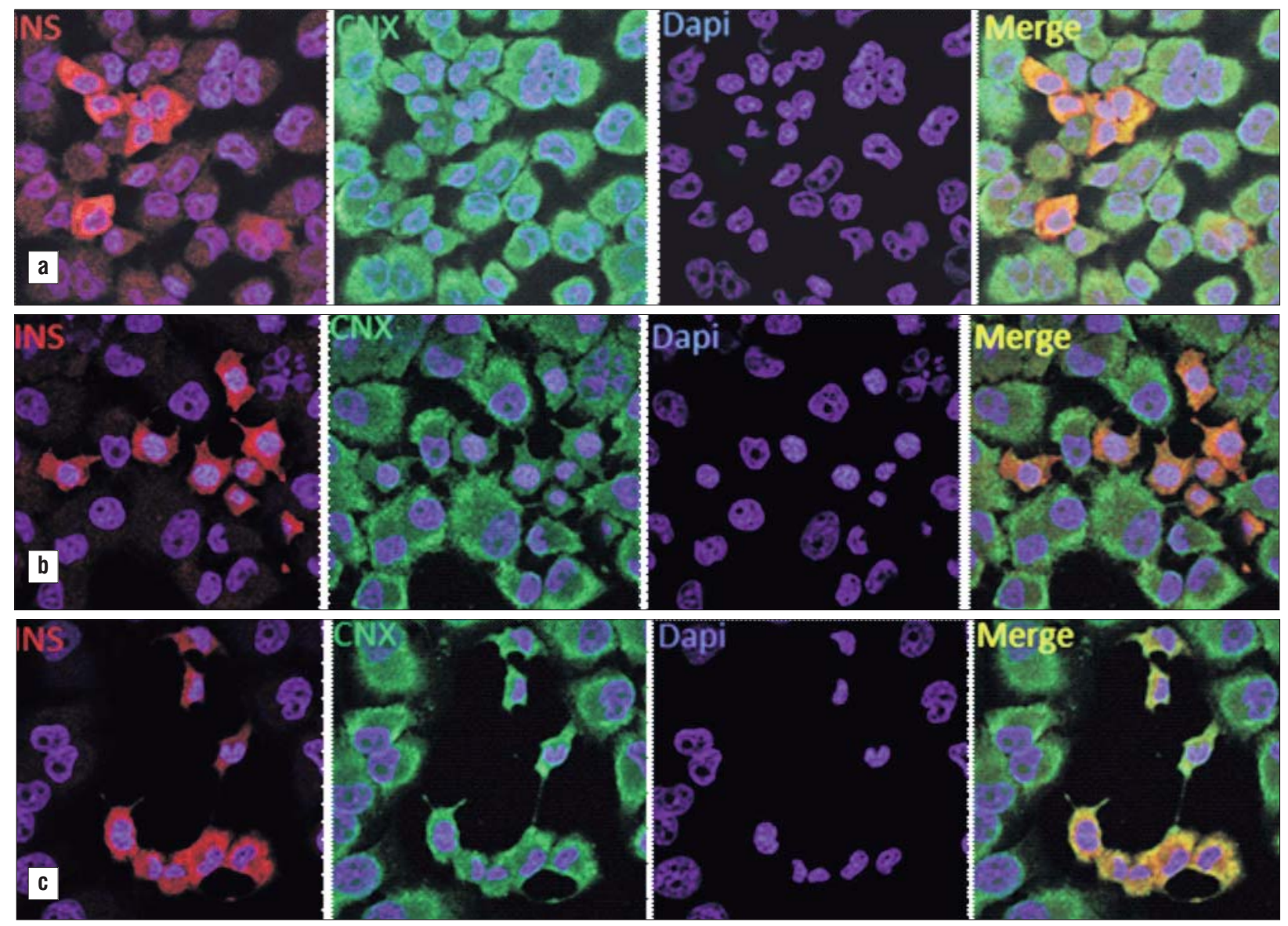

Figure 5 - Identical expression of calnexin but selective expression of insulin in 1.1B4 cells $(\mathrm{a}, \mathrm{b}, \mathrm{c})$

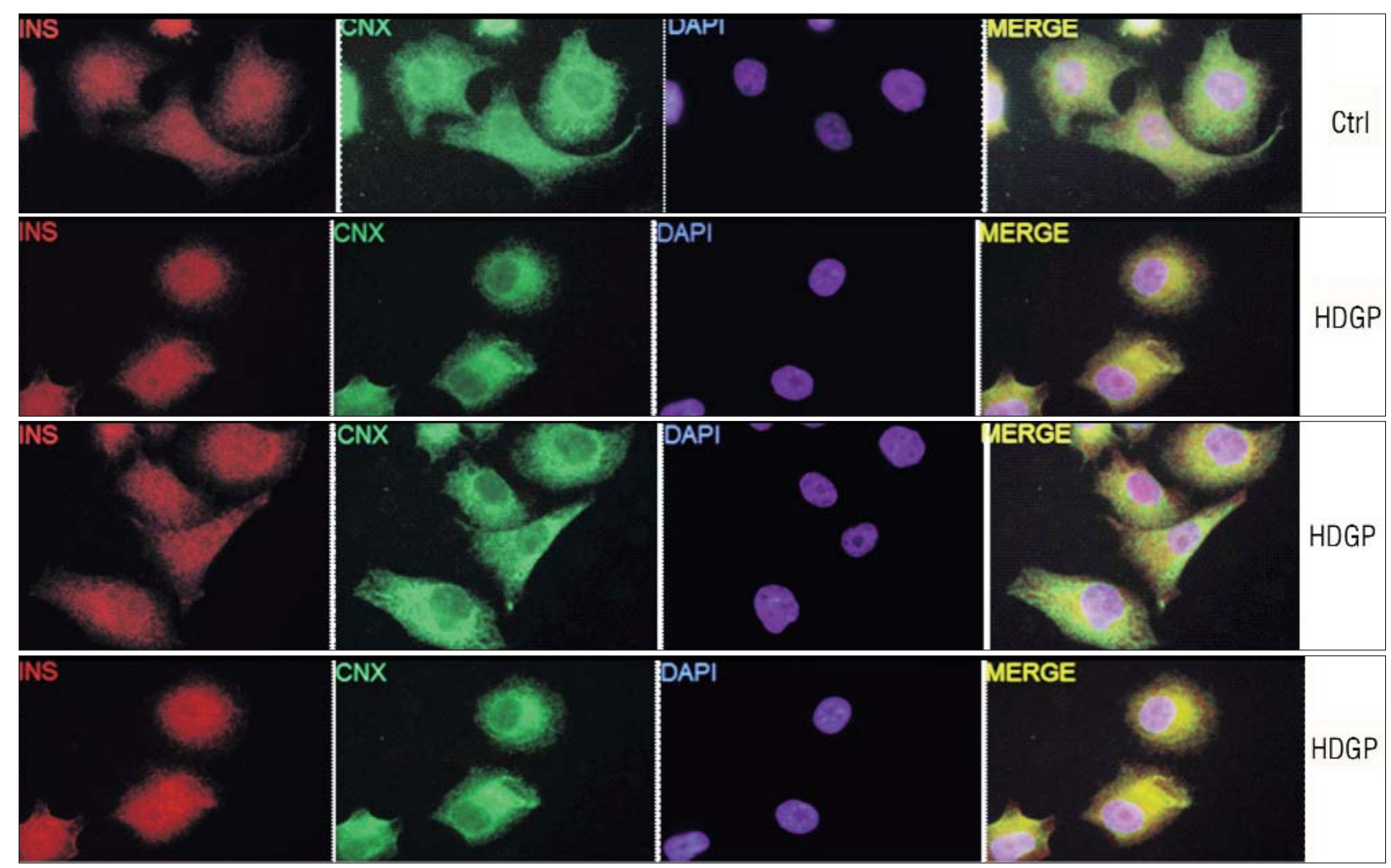

Figure 6 a - HDGP effects on 1.1B4 cell line 

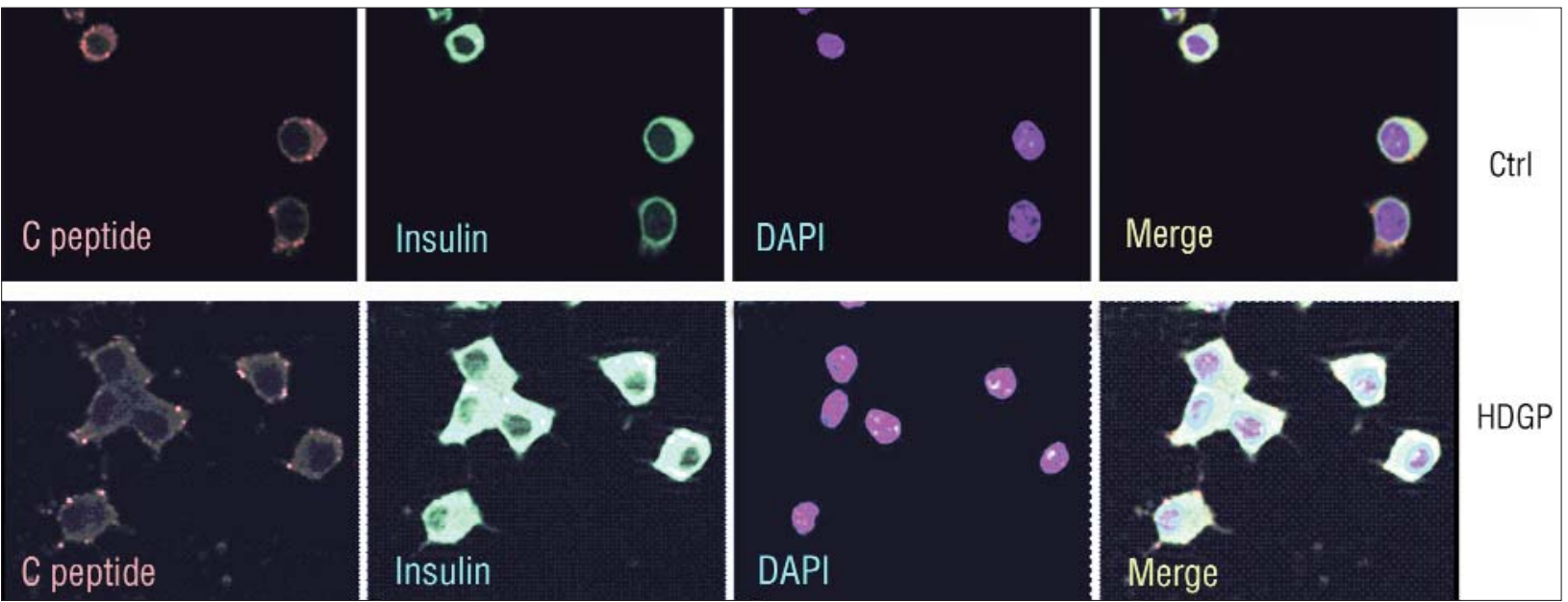

Figure 6 b - HDGP effects on INS-1E cell line
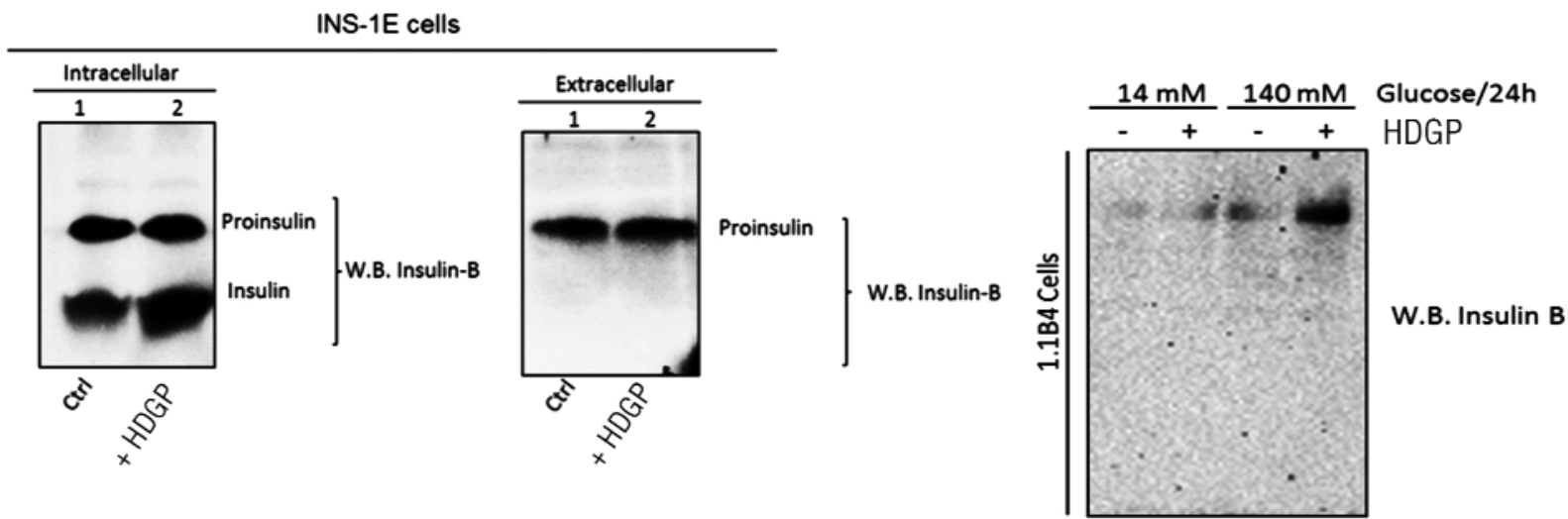

Figure 7 - Western blot analysis of insulin stimulation in INS-1E $(a, b)$ and 1.1B4 (c) cells irradiated with HDGP

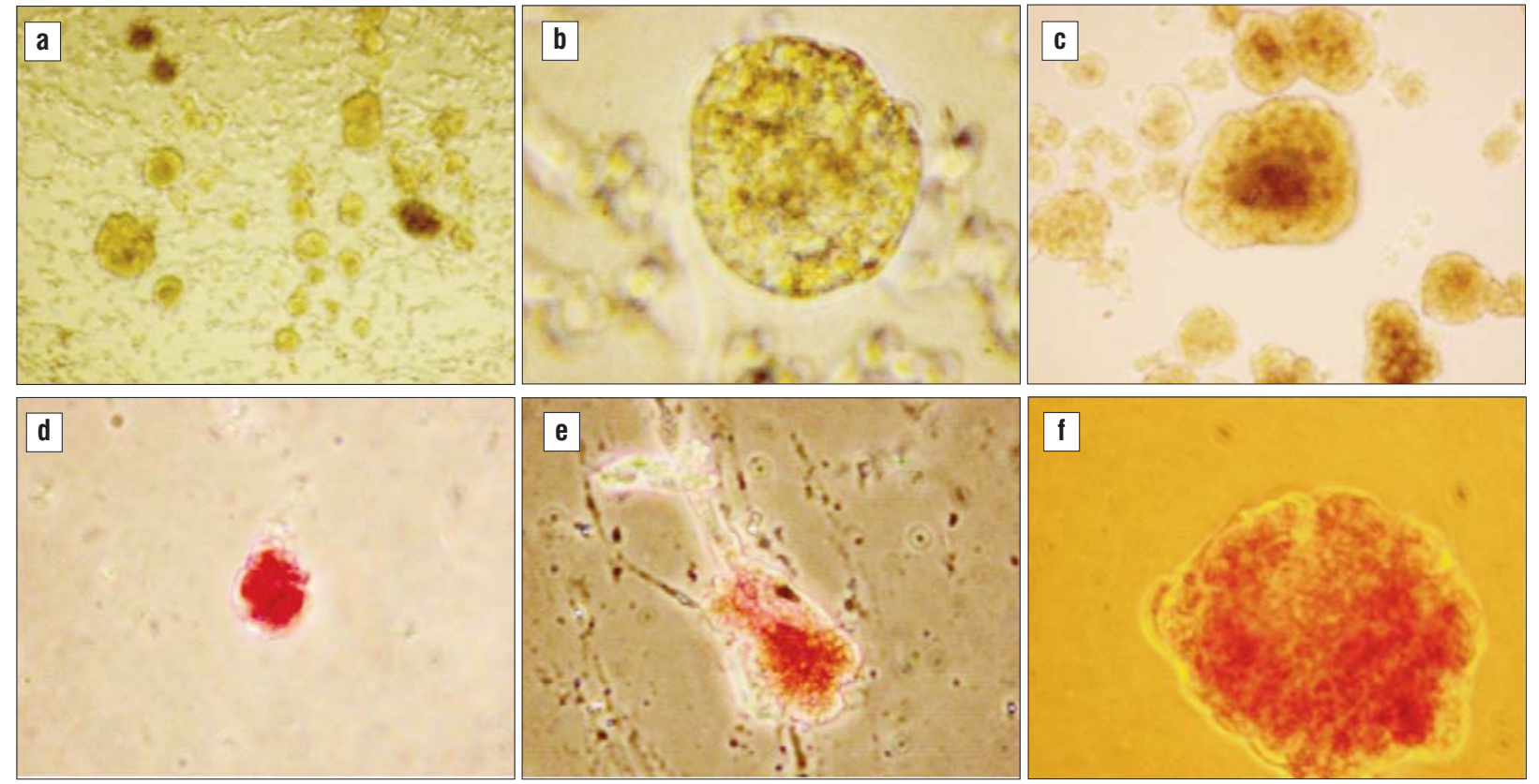

Figure 8- Human pancreatic islets cultured on inserts $(a, b)$, in suspensie $(c, d, e)$ and dithizone staining $(d, e, f)$ 

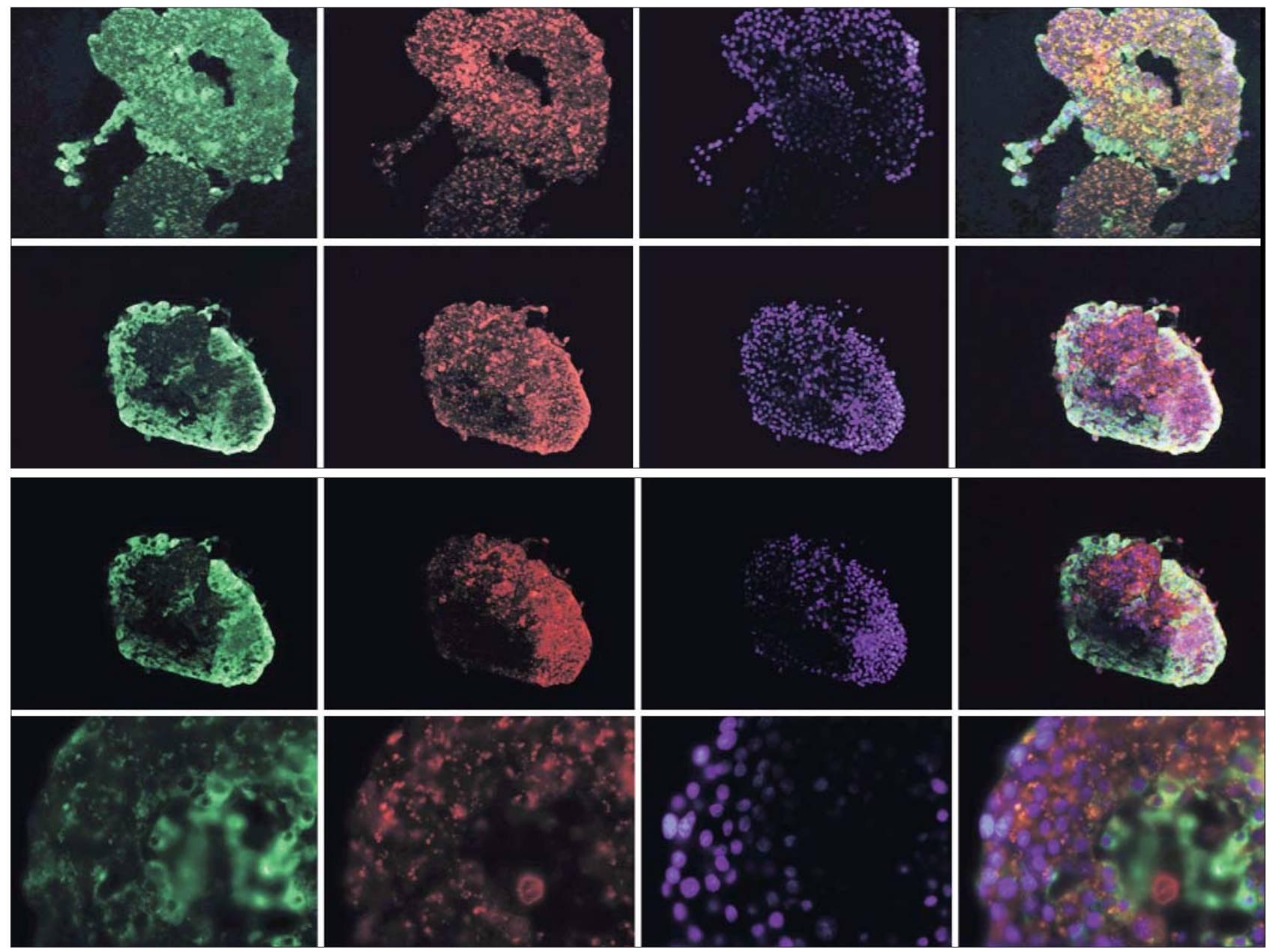

Figure 9 - Immunofluorescence staining of whole islets for insulin (green), glucagon (red) and nuclei (blue)
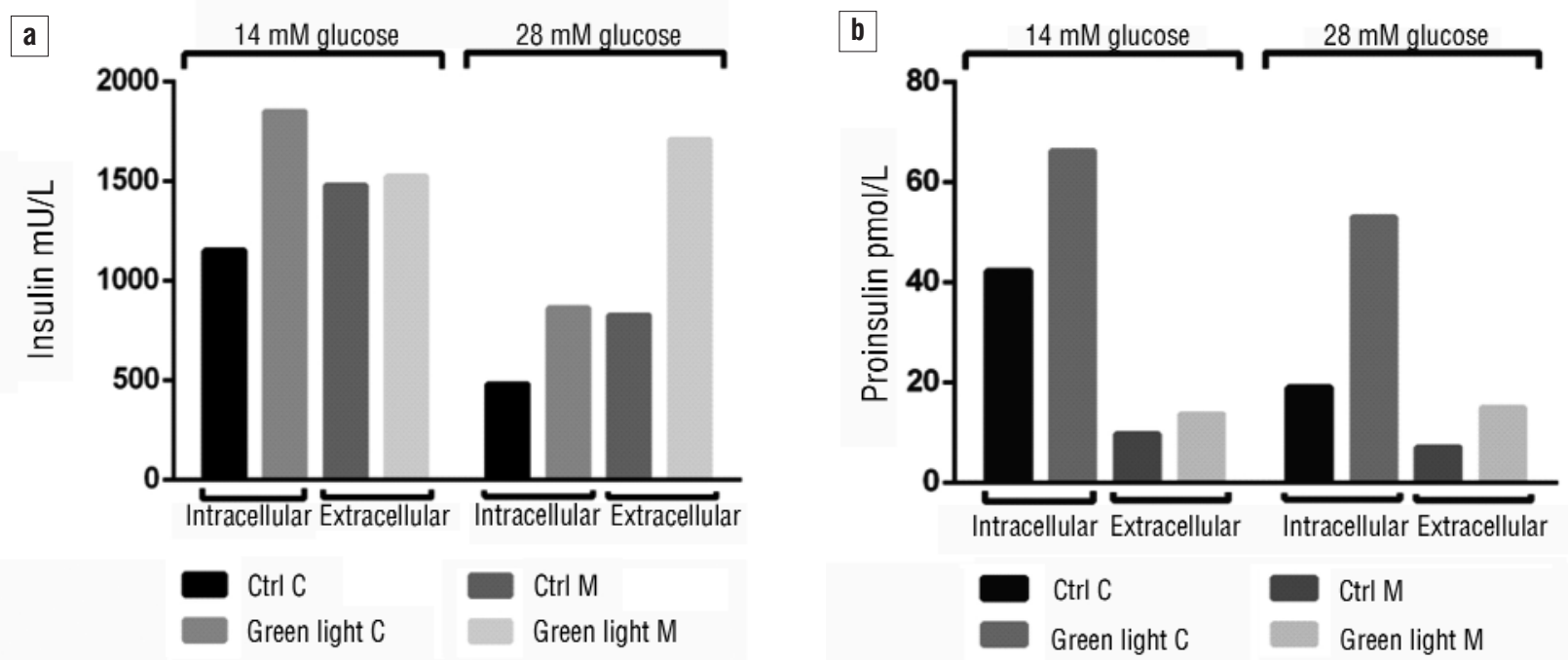

Figure 10 - Intracelllar and extracelllar modfications of insulin (a) and pro-insulin (b) in control and HDGP irradiated human primary pancreatic islets (ELISA) 

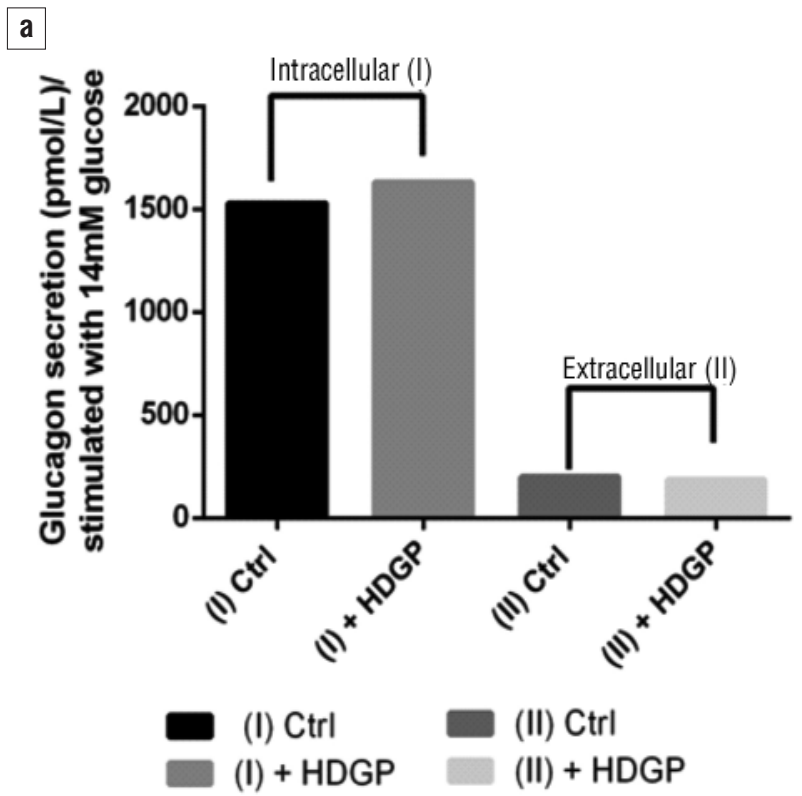

b

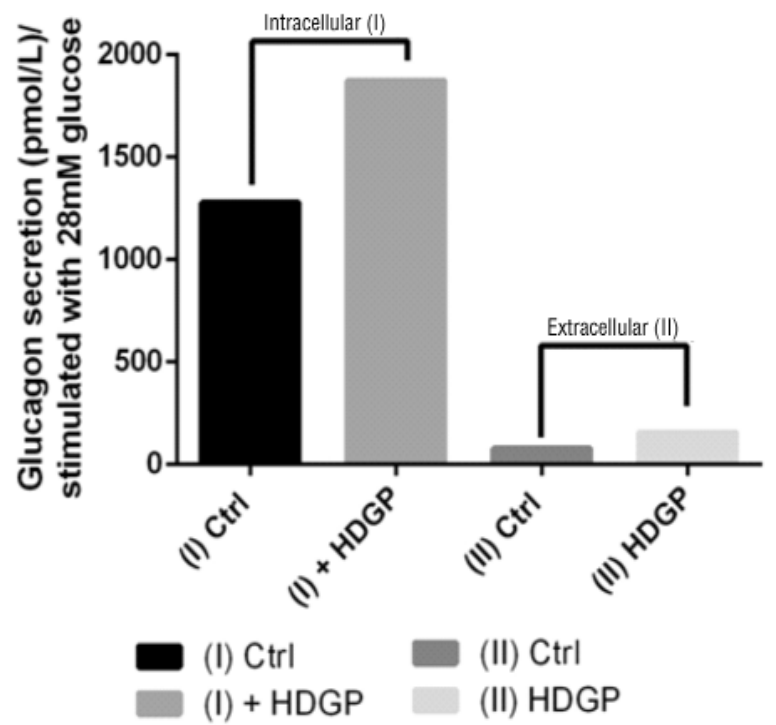

Figure 11 - Intracellar and extracellar modfications of glucagon in control and HDGP irradiated human primary pancreatic islets stimulated with glucose: $14 \mathrm{mM}$ (a) and $28 \mathrm{mM}$ (b)

\section{CONCLUSIONS}

Our results regarding the characterization of 1.1B4 cells (culture and growth, insulin expression and secretion, staining with human specific antibodies, glucose responsiveness, etc) confirmed the human identity and the inherited properties of functional beta cells.

We consider that the 1.1B4 cell line present good attributes which recommend it to be used for further studies of human beta cells and pancreatic islet transplantation.

The mechanism of stimulatory action of green photons on cellular systems is still unknown and remains to be elucidate. Nevertheless, the present study revealed functional modifications induced by HDGP irradiation in two beta pancreatic cell lines and in human primary pancreatic islets. Our results suggest that HDGP could be used as a stimulatory factor in cell cultures, prior to transplantation or in other regenerative medicine procedures.

\section{Founding source}

This study was financially supported by the Romanian Program for Research, Development and Innovation, research grant PN ID 139/5.10.2011, PNII-PT-PCCA 90/2011 and POSDRU/186/3.2/S/155295.

\section{Acknowledgements}

We are indebted to Dr. Norica Nichita for her critical reading of the manuscript.

\section{REFERENCES}

1. Skelin M, Rupnik M, Cencic A. Pancreatic beta cell lines and their applications in diabetes mellitus research. ALTEX. 2010;27(2):105-13.

2. Scharfmann R, Rachdi L, Ravassard P. Concise review: in search of unlimited sources of functional human pancreatic beta cells. Stem Cells Transl Med. 2013 Jan;2(1):61-7. doi: 10.5966/sctm.2012-0120. 3.

Kim B, Lin MZ. Optobiology: optical control of biological processes via protein engineering. Biochem Soc Trans. 2013 Oct;41(5):1183-8. doi: 10.1042/BST20130150.

4. Comorosan S, Polosan S, Jipa S, Popescu I, Marton G, Ionescu E, et al. Green light radiation effects on free radicals inhibition in cellular and chemical systems. J Photochem Photobiol B. 2011 Jan 10;102(1):3944. doi: 10.1016/j.jphotobiol.2010.09.003. Epub 2010 Sep 21.

5. Comorosan S, Polosan S, Popescu I, Ionescu E, Mitrica R, Cristache $\mathrm{L}$, et al. State Structural studies on serum albumins under green light irradiation. Eur Biophys J. 2010 Oct;39(11):1483-91. doi: 10.1007/ s00249-010-0606-y. Epub 2010 May 16.

6. Farcasanu IC, Mitrica R, Cristache L, Nicolau I, Ruta LL, Paslaru L, et al. Optical manipulation of Saccharomyces cerevisiae cells reveals that green light protection against UV irradiation is favored by low $\mathrm{Ca} 2+$ and requires intact UPR pathway. FEBS Lett. 2013 Nov 1;587(21): 3514-21. doi: 10.1016/j.febslet.2013.09.008. Epub 2013 Sep 19.

7. Mitrica R, Popescu I, Paslaru L, Badila D, Polosan S, Cristache L, et al. High-density green photons effects on $\mathrm{NaCl}$ solutions detected by red blood cells membranes. Digest Journal of Nanomaterials and Biostructures. 2012;7(1):227-35.

8. Comorosan S, Popescu I, Polosan S, Parvu C, Ionescu E, Paslaru L, et al. Conformational changes and metastable states induced in proteins by green light. Eur. Phys. J. B. 2015;88:8.

9. Paslaru L, Nastase A, Stefan L, Florea R, Sorop A, Ionescu E, et al. Stimulatory and possible antioxidant effects of High Density Green 
Photons (HDGP) on cellular systems. J Med Life. 2014 Oct-Dec 7(4):619-22.

10. Halevy O, Piestun Y, Rozenboim I, Yablonka-Reuveni Z. In ovo exposure to monochromatic green light promotes skeletal muscle cell proliferation and affects myofiber growth in posthatch chicks. Am J Physiol Regul Integr Comp Physiol. 2006 Apr;290(4):R1062-70.

11. Rozenboim I, El Halawani ME, Kashash Y, Piestun Y, Halevy 0. The effect of monochromatic photostimulation on growth and development of broiler birds. Gen Comp Endocrinol. 2013 Sep 1;190:214-9. doi: 10.1016/j.ygcen.2013.06.027. Epub 2013 Jul 15.

12. AlGhamdi KM, Kumar A, Moussa NA. Low-level laser therapy: a useful technique for enhancing the proliferation of various cultured cells.Lasers Med Sci. 2012 Jan;27(1):237-49. doi: 10.1007/s10103011-0885-2. Epub 2011 Jan 28.
13. Anwer AG, Gosnell ME, Perinchery SM, Inglis DW, Goldys EM. Visible $532 \mathrm{~nm}$ laser irradiation of human adipose tissue-derived stem cells: effect on proliferation rates, mitochondria membrane potential and autofluorescence. Lasers Surg Med. 2012 Nov;44(9):769-78. doi: 10.1002/lsm.22083. Epub 2012 Oct 9.

14. McCluskey JT, Hamid M, Guo-Parke H, McClenaghan NH, Gomis R, Flatt PR. Development and functional characterization of insulinreleasing human pancreatic beta cell lines produced by electrofusion. J Biol Chem. 2011 Jun 24;286(25):21982-92. doi: 10.1074/ jbc.M111 . 226795. Epub 2011 Apr 22.

15. Natalicchio A. Culture, passaging, nucleic acids and proteins extraction 1.1B4 cell line. Universita degli studi di Bari Aldo Moro-Corso in biotecnologie applicate alla fisiopatologia endocrina. Anno Accademico. 2015/2016. 